\title{
Epilepsi hos eldre
}

BAKGRUNN Både diagnostikk og behandling kan være vanskelig hos personer som får epilepsi etter fylte 65 år. Epilepsi er en av de vanligste nevrologiske tilstandene hos eldre, og forekomsten av nyoppstått epilepsi hos eldre er økende. Hensikten med denne artikkelen er å gi noen råd om håndtering av epilepsi hos denne pasientgruppen.

KUNNSKAPSGRUNNLAG Artikkelen bygger på et skjønnsmessig utvalg originalartikler og oversiktsartikler funnet i PubMed med søkekombinasjon «epilepsy and elderly» samt forfatternes egne erfaringer.

RESULTATER Anfallene, som som oftest er av fokal type, blir ikke sjelden oversett eller mistolket. Cerebrovaskulær sykdom er årsaken hos rundt halvparten. Ved valg av antiepileptikum er det viktig å ta hensyn til fysiologiske aldersforandringer og komorbide tilstander. Fordi det hos eldre er et smalere terapeutisk vindu enn hos yngre og høyere følsomhet for kognitive og andre bivirkninger, er det særlig viktig med lav startdose og langsom doseopptrapping.

FORTOLKNING Man kan ikke ekstrapolere resultater fra studier av yngre epilepsipasienter til de eldre. Det er derfor behov for flere studier rettet spesifikt mot denne pasientgruppen. Vi anbefaler som hovedregel ikke oppstart av enzyminduserende medikamenter, slike som fenytoin, fenobarbital og karbamazepin, blant annet på grunn av deres høye interaksjonspotensial.

Til tross for at epilepsi sannsynligvis er underdiagnostisert blant eldre $(1,2)$, er både insidens og prevalens av epilepsi nå høyere blant dem som er over 65 år enn i noen annen aldersgruppe $(3,4)$. Den økte forekomsten av hjerneslag og nevrodegenerative sykdommer i befolkningen har gjort epilepsi til en av de vanligste nevrologiske tilstandene hos eldre $(5,6)$. En fersk amerikansk studie av personer over 65 år viste en årlig insidensrate på 240/100 000 innbyggere (7), mens den i den generelle befolkningen er estimert til 33-52/100 $000(8,9)$. En norsk studie med 1053 sykehjemsbeboere viste at rundt $8 \%$ hadde epilepsi og at $11 \%$ brukte antiepileptika (10).

Det er to kategorier eldre med epilepsi: De som er blitt gamle med en epilepsi de har hatt i mange år, og de som har fått epilepsidiagnosen etter fylte 65 år. Denne artikkelen omhandler hovedsakelig den siste kategorien.

\section{Kunnskapsgrunnlag}

Denne oversikten bygger på forfatternes egne erfaringer med pasientgruppen og et skjønnsmessig utvalg av original- og oversiktsartikler, hovedsakelig engelskspråklige, funnet i PubMed etter et litteratursøk med søkekombinasjonen «elderly and epilepsy». Søket ble avsluttet i mai 2012.

\section{Etiologi}

Årsakene til epilepsi i denne aldersgruppen skiller seg fra årsakene i yngre kohorter, idet cerebrovaskulær sykdom er den domine- rende etiologien (11). Risikoen for epilepsi etter et hjerneslag avhenger forst og fremst av slagets størrelse og lokalisering (12-15). Det er større risiko for epilepsiutvikling etter hjerneblødning enn etter hjerneinfarkt (16), og personer med store frontotemporale kortikale lesjoner er spesielt utsatt (17). En prospektiv studie med nærmere 2000 personer med gjennomgått hjerneslag viste at ni måneder etter slaget hadde $8,9 \%$ hatt ett eller flere epileptiske anfall (12). En norsk studie viste at 3,1 \% av dem med gjennomgått hjerneslag hadde utviklet epilepsi, dvs. gjentatte uprovoserte anfall, etter 7-8 år (18). Det er ca. 15000 nye slagtilfeller i Norge per år (19), noe som betyr at rundt 460 nordmenn får postapoplektisk epilepsi hvert år.

Epileptiske anfall hos eldre kan også være en forløper for slag. En studie viste at epilepsidebut $\mathrm{i}$ denne aldersgruppen var assosiert med markert økt risiko for hjerneslag (20). Hos slike pasienter er derfor viktig å redusere risikofaktorer som for eksempel hypertensjon, hyperlipidemi, diabetes og røyking.

Epileptiske anfall som opptrer de første dagene etter for eksempel et cerebrovaskulært insult, et hodetraume eller høyt akoholinntak, kalles provoserte eller akutte symptomatiske anfall (21). Slike anfall er ikke ensbetydende med senere epilepsiutvikling og fordrer ikke behandling med antiepileptika.

Dukker det derimot opp epileptiske anfall mer enn to uker etter et hjerneslag, regnes disse som uprovoserte og blir ansett som debut av epilepsi. Man antar at disse anfal-

\section{Karl 0. Nakken}

karl.otto.nakken@ous-hf.no

Avdeling for kompleks epilepsi - SSE

Erik Sætre

Avdeling for nevrohabilitering

Rune Markhus

Avdeling for kompleks epilepsi - SSE

\section{Morten I. Lossius}

Avdeling for kompleks epilepsi - SSE

Klinikk for kirurgi og nevrofag

Oslo universitetssykehus

Se også kunnskapsprøve på www.tidsskriftet.no/quiz

\section{HOVEDBUDSKAP}

Det er nå høyere forekomst av epilepsi hos dem over 65 år enn hos barn og unge

Epileptiske anfall hos eldre blir ofte oversett eller mistolket

Ved behov for antiepileptisk behandling kan lamotrigin, levetiracetam eller zonisamid være gunstige førstevalg i denne pasientgruppen

Hos eldre er det særlig viktig med lav startdose og langsom doseopptrapping 
lene skyldes et hypereksitabelt cellenettverk som er oppstått som følge av en synaptisk reorganisering i lesjonens randsone (22).

Ved siden av cerebrovaskulær sykdom finnes det flere andre årsaker til nyoppstått epilepsi hos eldre, blant annet metabolsk/ toksisk sykdom, hjernesvulst, nevrodegenerativ sykdom, hodetraumer og sentralnervøse infeksjoner (9). Epilepsi forekommer hos $8-10 \%$ av dem med Alzheimers sykdom, særlig utsatt er de med tidlig sykdomsdebut (23). Hos rundt en tredel av pasienter med primære eller sekundære hjernesvulster er epileptiske anfall debutsymptomet (24).

\section{Anfallstyper}

De aller fleste med epilepsidebut etter fylte 65 år har fokale epilepsier med enkle eller komplekse partielle anfall, dvs. fokale anfall uten eller med påvirket bevissthet (25). Av disse er komplekse partielle anfall hyppigst og utgjør vel $40 \%(1,11)$. Tendensen til generalisering av den epileptiske aktiviteten blir mindre med årene, og sekundærgeneraliserte tonisk-kloniske anfall ses sjeldnere hos personer over 60 år enn hos yngre $(26 \%$ versus $65 \%)(26)$.

Mens temporallappen ofte er sete for epilepsi hos yngre voksne, er den epileptogene sonen oftere lokalisert til frontallappen eller parietallappen ved nyoppstått epilepsi hos eldre $(27,28)$. Det er årsaken til at man sjeldnere ser klassiske temporallappsanfall med fjernhet og orofaciale automatismer (smatting, tygging, svelging) hos eldre enn hos yngre.

Eldre har sjelden forvarsler eller aura (5), og anfallene kan være svært diskré og ytre seg som for eksempel forbigående svimmelhet, ustøhet, fall eller forvirring. Den postiktale forvirringen varer gjerne lenger hos eldre enn hos yngre, det samme gjelder postiktale pareser (Todds pareser) (2, 27-29).

Konvulsiv status epilepticus er en livstruende tilstand, og en studie viste en årlig insidens hos dem over 60 år på 86/100 000 personer (28). Mortaliteten ved status epilepticus er først og fremst avhengig av den tilgrunnliggende årsaken. Dessuten øker mortaliteten med varigheten av status og med økende alder. I en studie fant man en mortalitet på $38 \%$ hos dem over 60 år og en mortalitet på nesten $50 \%$ hos dem over 80 år (30). Ikke-konvulsiv status epilepticus, oftest i form av komplekse partielle anfall som kan vare i timer eller dager og som ytrer seg som fjernhet og forvirring, blir ofte ikke erkjent (31).

\section{Diagnostikk}

Fordi anfallene hos eldre kan ytre seg svært forskjellig og kan være vanskelige å tolke, forblir mange epileptiske anfall i denne aldersgruppen udiagnostisert. En studie viste at bare $21 \%$ av eldre med komplekse partielle anfall fikk korrekt diagnose (32). Anfallene blir ofte mistolket som uspesifikke aldersfenomener, synkoper, medikamentbivirkninger, vaskulære episoder eller demens (33).

Som ved alle nevrologiske sykdommer er en grundig sykehistorie med komparentopplysninger selve hjørnesteinen i diagnostikken. Eldre med nyoppståtte epilepsisuspekte anfall bør innlegges i den lokale nevrologiske avdelingen. Her må man alltid utelukke kardiale, infeksiøse, toksiske eller metabolske årsaker til anfallene og samtidig huske på epilepsi som en mulighet. Cerebral MR-undersøkelse med kontrast bør gjøres for å avdekke cerebrovaskulær sykdom eller annen cerebral patologi. MR-undersøkelse kan hos noen vise aldersforandringer som for eksempel diffus cerebral atrofi og/eller periventrikulære signalforandringer. Vår erfaring er at slike forandringer som regel $i k k e$ er årsak til anfallene.

Alle med epilepsisuspekte anfall bør få EEG-undersøkelse. For å stille en sikker epilepsidiagnose er langtids-EEG-monitorering med opptak av anfall på video selve gullstandarden (34). Dessverre har interiktal EEG begrenset verdi på grunn av lav sensitivitet og spesifisitet. Eldre har lavere forekomst av interiktal epileptiform aktivitet sammenliknet med yngre, mens de oftere har uspesifikke EEG-forstyrrelser (35). Det er viktig å minne om at epilepsi er en klinisk diagnose og at fravær av epileptiform aktivitet i EEG ikke må tolkes som bevis på at det ikke foreligger epilepsi.

\section{Behandling}

Mens man hos yngre voksne vanligvis venter med å iverksette antiepileptisk behandling til vedkommende har hatt to sikre epileptiske anfall, anbefaler vi å starte slik behandling etter bare ett anfall hos eldre (35). Det gjelder også om EEG ikke viser epileptiform aktivitet. Dette fordi de fleste eldre erfaringsmessig har et morfologisk substrat for anfallene. Risikoen for nye anfall etter å ha hatt ett er derfor større hos eldre enn hos yngre (80\% versus $40 \%$ ) (36).

\section{Endret famakokinetikk og -dynamikk}

Har man stilt epilepsidiagnosen, er farmakologisk behandling førstevalget. Målet er alltid anfallsfrihet uten sjenerende bivirkninger. Ved valg av antiepileptikum er det viktig å ta hensyn til både medikamentrelaterte og pasientrelaterte faktorer. Særlig er det viktig å være oppmerksom på aldersrelaterte farmakokinetiske og farmakodynamiske endringer (37).

Farmakodynamiske endringer gir, muligens på grunn av lavere reseptortetthet, økt følsomhet for bivirkninger, særlig av kognitiv art $(38,39)$.

Selv om det er store individuelle variasjoner, har mange eldre mindre kroppsvæske og redusert lever- og nyrefunksjon, noe som kan påvirke farmakokinetikken av flere legemidler, med endret absorpsjon, distribusjon, metabolisme og utskilling. Dessuten kan lave albuminnivåer bidra til at den frie farmakologisk aktive delen av et legemiddel blir høyere. Dette gjelder særlig høygradige proteinbundne legemidler som valproat, karbamazepin og fenytoin. Dette betyr at mange antiepileptika hos eldre får et enda smalere terapeutisk vindu, og at legemidlenes referanseområder ikke har samme gyldighet for eldre som for yngre (37).

Den gamle reglen om «start low, go slow» gjelder i enda høyere grad for eldre enn for yngre, og vårt råd er å starte med halvparten av anbefalt startdose og bruke dobbelt så lang doseopptrappingstid som anbefalt ellers. Måldosen bør bestemmes mer av kliniske faktorer enn av serumkonsentrasjonsmålinger.

\section{Valg av antiepileptikum}

Mange eldre har en rekke sykdommer og tilsvarende polyfarmasi. En studie fra norske sykehjem viste at beboerne $\mathrm{i}$ gjennomsnitt brukte sju legemidler (9). Det er nødvendig med individuell vurdering, og eldre epilepsipasienter bør helst få et antiepileptikum med lavt interaksjonspotensial. De eldre enzyminduserende medikamentene som fenobarbital, fenytoin og karbamazepin bør derfor helst unngås i denne pasientgruppen (40), i hvert fall hos dem som bruker flere legemidler. Fenytoin og karbamazepin gir dessuten øt risiko for kardiale arytmier (41), de kan fremme osteoporose (42) og øker muligens også risikoen for vaskulær sykdom (43). Trass i disse motforestillingene er fenytoin og fenobarbital stadig de mest brukte antiepileptika blant eldre $(10,37,44)$.

Selv om den anfallsdempende effekten av antiepileptika er bedre hos eldre enn hos yngre, blir ikke alle anfallsfrie (45). De få randomiserte kliniske studiene som er gjort 
i denne pasientgruppen, har vist relativt små forskjeller i effekt mellom nye og gamle antiepileptika (46-49). De nye synes å gi færre bivirkninger. Retensjonsraten hos 417 eldre pasienter, dvs. andelen som fortsatt brukte legemidlet etter 12 måneders behandling, varierte mellom de seks mest brukte medikamentene fra $79 \%$ for lamotrigin til $48 \%$ for karbamazepin i en studie (50). Høyest andel anfallsfrihet ble funnet hos dem som brukte lamotrigin og levetiracetam, henholdsvis $54 \%$ og $43 \%(50)$.

Lamotrigin, levetiracetam og zonisamid fremstår etter vårt skjønn som gunstige førstevalg på grunn av god balanse mellom effekt og tolerabilitet, lavt interaksjonspotensial og relativt lange halveringstider, som tillater bare 1-2 døgndoser. Etter langsom doseopptrapping er vårt forslag til første måldose av lamotrigin $100 \mathrm{mg} /$ døgn, enten som monodose eller som $50 \mathrm{mg} \times 2$, av levetiracetam $1000 \mathrm{mg} /$ døgn som $500 \mathrm{mg} \times 2$, av zonisamid $100 \mathrm{mg} / \mathrm{d} ø g n$ som monodose.

Nye antiepileptika som eslikarbazepinacetat, lakosamid og retigabin kan også være aktuelle alternativer, men vi har foreløpig liten erfaring med disse.

Viktig å sikre at medikamentene tas riktig Med en omfattende polyfarmasi kan det være vanskelig for mange eldre å holde styr på medisininntaket. Ved epilepsi hos eldre er det derfor viktig med en så enkel behandling som mulig. Man bør tilstrebe monoterapi, helst også monodose. Dags- eller ukedosett samt hyppige polikliniske kontroller kan gi bedre behandlingsetterlevelse.

\section{Ikke-farmakologisk behandling}

Hos eldre som ikke oppnår akseptabel anfallskontroll med medikamenter, kan det noen ganger være aktuelt å vurdere epilepsikirurgi eller vagusnervestimulering. Det er gjort få studier av epilepsikirurgi hos eldre. Andelen anfallsfrie etter slik kirurgi er noe lavere hos eldre enn hos yngre (51), og det er økt risiko for nevropsykologiske sekveler (52).

Eldre har samme anfallsdempende effekt av vagusnervestimulering som yngre, idet $50-60 \%$ av pasientene får minst $50 \%$ reduksjon av anfallsfrekvensen etter ett års behandling (53). Ved siden av den anfallsdempende effekten kan vagusnervestimulering også ha en antidepressiv effekt (54).

\section{Store konsekvenser \\ for livskvaliteten}

$\AA$ få uforutsigbare epileptiske anfall i alderdommen, ofte i tillegg til andre sykdommer, skaper gjerne engstelse og utrygghet. Anfallene gjør at mange taper muligheten for å leve et selvstendig liv. Tap av førerkort kan ytterligere bidra til isolasjon og ensomhet. Anfallsrelaterte fallskader kan dessuten få alvorligere konsekvenser $\mathrm{i}$ denne aldersgruppen enn for yngre.

\section{Konklusjon}

Både insidens og prevalens av epilepsi er $i$ dag høyere hos den eldre enn $i$ den yngre delen av befolkningen. Likevel er kunnskapen om og forskningen på eldre og epilepsi overraskende liten. Anfallsutforming som kan være vanskelig å tolke, kognitiv svikt og uspesifikke funn ved MR- og EEG-undersøkelser vanskeliggjør diagnostikken. Fastlegene bør henvise alle eldre med epilepsisupekte anfall til utredning og eventuell oppstart av behandling ved lokal nevrologisk avdeling.

Ved valg av behandling må man ta hensyn til aldersbetingede farmakokinetiske og farmakodynamiske endringer, komorbiditet og komedikasjon. Antiepileptika med lavt interaksjonpotensial, for eksempel lamotrigin, levetiracetam eller zonisamid, er derfor etter vår vurdering gunstige valg hos eldre. Vi anbefaler lavere startdose, langsommere doseopptrappingstakt og lavere måldose enn for yngre voksne.

\section{Karl O. Nakken (f. 1945)}

er dr.med., spesialist i nevrologi og medisinsk sjef ved Avdeling for kompleks epilepsi - SSE.

Forfatter har fylt ut ICMJE-skjemaet og oppgir følgende interessekonflikter: Han har mottatt foredragshonorar fra GSK og Eisai og støtte til kongressdeltakelse fra GSK.

\section{Erik Sætre (f. 1960)}

er spesialist i nevrologi og fra 1.1. 2013 overlege ved Avdeling for kompleks epilepsi - SSE. Han har disputert på studier av epilepsi hos eldre. Forfatter har fylt ut ICMJE-skjemaet og oppgir ingen interessekonflikter.

\section{Rune Markhus (f. 1961)}

er spesialist i nevrologi og i klinisk nevrofysiologi. Han er seksjonsleder ved Avdeling for kompleks epilepsi - SSE.

Forfatter har fylt ut ICMJE-skjemaet og oppgir ingen interessekonflikter.

\section{Morten I. Lossius (f. 1962)}

er dr.med., spesialist i nevrologi, overlege ved Avdeling for kompleks epilepsi - SSE og leder av forskningsgruppen «kompleks epilepsi» ved Oslo universitetssykehus.

Forfatter har fylt ut ICMJE-skjemaet og oppgir følgende interessekonflikter: Han har mottatt foredragshonorar fra UCB, GSK og Eisai og støtte til kongressdeltakelse fra UCB.

\section{Litteratur}

1. Rowan AJ, Ramsay RE, Collins JF et al. New onse geriatric epilepsy: a randomized study of gabapen tin, lamotrigine, and carbamazepine. Neurology 2005; 64: 1868-73

2. Silveira DC, Jehi L, Chapin J et al. Seizure semiology and aging. Epilepsy Behav 2011; 20 $375-7$

3. Banerjee PN, Hauser WA. Incidence and prevalence. I: Engel J jr., Pedley T, red. Epilepsy com prehensive textbook. 2. utg. Philadelphia, PA: Wolters Kluwer, Lippincott Williams \& Wilkins, 2008: $45-56$
4. Svendsen T, Lossius M, Nakken KO. Age-specific prevalence of epilepsy in Oppland County, Norway. Acta Neurol Scand 2007; 116: 307-11.

5. Werhahn KJ. Epilepsy in the elderly. Dtsch Arzteb Int 2009: 106: 135-42.

6. Verellen RM, Cavazos JE. Pathophysiological considerations of seizures, epilepsy, and status epilepticus in the elderly. Aging Dis 2011; 2: 278-85.

7. Faught E, Richman J, Martin R et al. Incidence and prevalence of epilepsy among older U.S. Medicare beneficiaries. Neurology 2012; 78: 448-53.

8. Zarrelli MM, Beghi E, Rocca WA et al. Incidence of epileptic syndromes in Rochester, Minnesota: 1980-1984. Epilepsia 1999: 40: 1708-14.

9. Olafsson E, Ludvigsson P, Gudmundsson $\mathrm{G}$ et al. Incidence of unprovoked seizures and epilepsy in Iceland and assessment of the epilepsy syndrome classification: a prospective study. Lancet Neurol 2005: 4: 627-34.

10. Rytter E, Nakken KO, Mørch-Reiersen LT et al. Bruk av antiepileptika hos sykehjemsbeboere. Tidsskr Nor Lægeforen 2007; 127: 1185-7.

11. Ettinger AB, Shinnar S. New-onset seizures in an elderly hospitalized population. Neurology 1993 43: 489-92.

12. Bladin CF, Alexandrov AV, Bellavance A et al. Seizures after stroke: a prospective multicenter study. Arch Neurol 2000; 57: 1617-22.

13. Lossius MI, Rønning OM, Slapø GD et al. Poststroke epilepsy: occurrence and predictors - a long-term prospective controlled study (Akershus Stroke Study). Epilepsia 2005; 46: 1246-51.

14. Kammersgaard LP. Olsen TS. Poststroke epilepsy in the Copenhagen stroke study: incidence and pre dictors. J Stroke Cerebrovasc Dis 2005; 14: 210-4.

15. Slapø GD, Lossius MI, Gjerstad L. Poststroke epilepsy: occurrence, predictors and treatment. Expert Rev Neurother 2006: 6: 1801 -9.

16. Burn J, Dennis M, Bamford J et al. Epileptic seizures after a first stroke: the Oxfordshire Community Stroke Project. BMJ 1997: 315: 1582-7.

17. Menon B. Shorvon SD. Ischaemic stroke in adults and epilepsy. Epilepsy Res 2009; 87: 1-11.

18. Lossius MI, Rønning OM, Mowinckel P et al. Incidence and predictors for post-stroke epilepsy. A prospective controlled trial. The Akershus stroke study. Eur J Neurol 2002: 9: 365-8.

19. Fjærtoft $\mathrm{H}$, Indredavik B. Kostnadsvurderinger ved hjerneslag. Tidsskr Nor Lægeforen 2007; 127 $744-7$

20. Cleary P, Shorvon S, Tallis R. Late-onset seizures as a predictor of subsequent stroke. Lancet 2004 363: $1184-6$

21. Beghi E, Carpio A, Forsgren L et al. Recommendation for a definition of acute symptomatic seizure. Epilepsia 2010: 51: 671-5

22. Camilo O, Goldstein LB. Seizures and epilepsy after ischemic stroke. Stroke 2004; 35: 1769-75.

23. Scarmeas N, Honig LS, Choi H et al. Seizures in Alzheimer disease: who, when, and how common? Arch Neurol 2009; 66: $992-7$

24. Maschio M, Dinapoli L. Lecture: profile of risks and benefits of new antiepileptic drugs in brain tumor related epilepsy. Neurol Sci 2011; 32 (suppl 2): S259-62.

25. Rowan AJ. Seizure. Fundamentals of drug management of epilepsy in the older patient. Geriatrics 2002; 57: 33-7.

26. Cloyd J, Hauser WA, Towne A et al. Epidemiological and medical aspects of epilepsy in the elderly. Epilepsy Res 2006; 68 (suppl 1): S39-48.

27. Ramsay RE, Rowan AJ, Pryor FM. Special conside rations in treating the elderly patient with epilepsy. Neurology 2004; 62 (suppl 2): S24-9.

28. Sheth RD, Drazkowski JF, Sirven JI et al. Protracted ictal confusion in elderly patients. Arch Neuro 2006; 63: 529-32

29. Ramsay RE, Pryor F. Epilepsy in the elderly. Neurology 2000: 55 (suppl 1): S9-14.

30. DeLorenzo RJ, Hauser WA, Towne AR et al. A prospective, population-based epidemiologic study of status epilepticus in Richmond, Virginia. Neurology 1996; 46: 1029-35.

31. Walker MC. Diagnosis and treatment of nonconvulsive status epilepticus. CNS Drugs 2001; 15 931-9

32. Spitz MC, Bainbridge JL, Winzenburg KV et al. Observation on the delay in diagosis of seizures in the elderly: update 3. Epilepsia 2003; 44 (suppl 9): 18 
33. Brodie MJ Elder AT, Kwan P. Epilepsy in later life. Lancet Neurol 2009; 8: 1019-30.

34. Drury I, Selwa LM, Schuh LA et al. Value of inpatient diagnostic CCTV-EEG monitoring in the elderly. Epilepsia 1999; 40: 1100-2.

35. Van Cott AC. Epilepsy and EEG in the elderly. Epilepsia 2002; 43 (suppl 3): 94-102.

36. Bergey GK. Initial treatment of epilepsy: special issues in treating the elderly. Neurology 2004; 63 (suppl 4): S40-8.

37. Leppik IE, Birnbaum AK. Epilepsy in the elderly. Ann N Y Acad Sci 2010; 1184: 208-24

38. Feely J, Coakley D. Altered pharmacodynamics in the elderly. Clin Geriatr Med 1990: 6: 269-83.

39. Read CL, Stephen LJ, Stolarek IH et al. Cognitive effects of anticonvulsant monotherapy in elderly patients: a placebo-controlled study. Seizure 1998; 7: 159-62.

40. Perucca E, Berlowitz D, Birnbaum A et al. Pharmacological and clinical aspects of antiepileptic drug use in the elderly. Epilepsy Res 2006; 68 (suppl 1): S49-63.

41. Tomson T. Kennebäck G. Arrythmia, heart rate variability, and antiepileptic drugs. Epilepsia 1997 38 (suppl 11): S48-51.

42. Mintzer S, Boppana P, Toguri J et al. Vitamin D levels and bone turnover in epilepsy patients taking carbamazepine or oxcarbazepine. Epilepsia 2006; 47: 510-5.
43. Chuang $\mathrm{Y}-\mathrm{C}$, Chuang $\mathrm{H}-\mathrm{Y}$, Lin T-K et al. Effects of long-term antiepileptic drug monotherapy on vascular risk factors and atherosclerosis. Epilepsia 2012; 53: 120-8

44. Galimberti CA, Magri F. Magnani B et al. Antiepileptic drug use and epileptic seizures in elderly nursing home residents: a survey in the province of Pavia, Northern Italy. Epilepsy Res 2006; 68: $1-8$

45. Mattson RH, Cramer JA, Collins JF et al. Comparison of carbamazepine, phenobarbital, phenytoin, and primidone in partial and secondarily generalized tonic-clonic seizures. N Engl J Med 1985; 313 $145-51$.

46. Stephen LJ, Kelly K, Mohanraj R et al. Pharmacological outcomes in older people with newly diagnosed epilepsy. Epilepsy Behav 2006; 8: 434-7.

47. Brodie MJ, Overstall PW, Giorgi L. Multicentre, double-blind, randomised comparison between lamotrigine and carbamazepine in elderly patients with newly diagnosed epilepsy. Epilepsy Res 1999 37: $81-7$.

48. Saetre E, Perucca E, Isojärvi J et al. An international multicenter randomized double-blind controlled trial of lamotrigine and sustainedrelease carbamazepine in the treatment of newly diagnosed epilepsy in the elderly. Epilepsia 2007; 48: 1292-302

49. Marson AG, Appleton R, Baker GA et al. A random- ised controlled trial examining the longer-term outcomes of standard versus new antiepileptic drugs. The SANAD trial. Health Technol Assess 2007: 11: iii-iv, ix-x, 1-134.

50. Arif $\mathrm{H}$, Buchsbaum R, Pierro J et al. Comparative effectiveness of 10 antiepileptic drugs in older adults with epilepsy. Arch Neurol 2010; 67: 408-15.

51. Sirven JI, Malamut BL, O'Connor MJ et al. Temporal lobectomy outcome in older versus younger adults. Neurology 2000; 54: 2166-70.

52. Grivas A, Schramm J, Kral T et al. Surgical treatment for refractory temporal lobe epilepsy in the elderly: seizure outcome and neuropsychological sequels compared with a younger cohort. Epilepsia 2006; 47: $1364-72$

53. Sirven JI, Sperling M, Naritoku D et al. Vagus nerve stimulation therapy for epilepsy in older adults. Neurology 2000; 54: 1179-82.

54. Kennedy SH, Giacobbe P. Treatment resistant depression-advances in somatic therapies. Ann Clin Psychiatry 2007; 19: 279-87.

Mottatt 29.6. 2012, første revisjon innsendt 18.10. 2012, godkjent 29.1. 2013. Medisinsk redaktør Merete Kile Holtermann. 